Open Access

\title{
Statistical analysis of orthographic and phonemic language corpus for word-based and phoneme-based Polish language modelling
}

\author{
Piotr Kłosowski
}

\begin{abstract}
This article presents the original results of Polish language statistical analysis, based on the orthographic and phonemic language corpus. Phonemic language corpus for Polish was developed by using automatic grapheme-to-phoneme conversion of the source orthographic language corpus, obtained from the National Corpus of Polish (NCP). The corpus contains the most frequently used Polish words, written with the use of phonemic notation. Performed statistical analysis of Polish language based on phonemic language corpus, includes frequency of occurrence calculation of the orthographic and phonemic language components, as well as their sequence. Statistical language data, obtained as a result of performed statistical analysis, enable to develop statistical word-based and phoneme-based language models for Polish. Applying these language models can effectively contribute to efficiency improvement of automatic speech recognition for Polish.
\end{abstract}

Keywords: Automatic grapheme-to-phoneme conversion, Automatic speech recognition, Language corpus, Language modelling, Language statistical analysis

\section{Introduction}

The main goal of automatic speech recognition (ASR) is translation of spoken words into a text [1]. Modern speech recognition systems require implementation of the acoustic and language modelling [2]. Both acoustic and language modelling are important parts of modern statistical speech recognition approach $[3,4]$. Statistical language modelling enables to develop large vocabulary and effective speech recognition systems [5]. Language modelling can be used not only in speech recognition application, but also in other areas of speech and language processing, e.g., language recognition, machine translation, part-of-speech tagging, parsing, handwriting recognition, information retrieval and other applications.

The main motivation of the research on speech recognition area, is to improve automatic speech recognition process, especially for Polish language $[6,7]$. Additionally,

Correspondence: pklosowski@polsl.pl

Department of Electronics, Faculty of Automatic Control, Electronics and

Computer Science, Silesian University of Technology, Akademicka 16, 44-100 Gliwice, Poland research studies have been conducted in the field of properties of Polish phonemes $[8,9]$, speech recognition based on it [10], speaker recognition [11, 12], speaker verification [13-15], and new applications of speech recognition, e.g., automatic speech translation [16].

Particularly, a good performance of automatic speech recognition is achieved with use of speech recognition by statistical methods [17]. Therefore, the main objective of the research presented in this paper, was to perform statistical analysis of Polish language based on the orthographic and phonemic language corpus, for development of statistical word-based and phoneme-based language models, as well as applying them to improve speech recognition for Polish. The development of statistical language models helps to predict a sequence of recognized spoken words and phonemes. The use of developed language models can effectively contribute to the improvement of the automatic speech recognition effectiveness, based on statistical methods. The development of wordbased and phoneme-based language models for speech recognition, built on statistical language data, requires 
the access to large orthographic and phonemic language corpora $[18,19]$.

\section{Orthographic language corpus}

One of the biggest orthographic Polish language corpus is the National Corpus of Polish (NCP) [20]. The NCP corpus is available for the scientific community and offers great flexibility, as well as it is extremely important in terms of scientific value. The NCP corpus provides crucial reference material reflecting the state of contemporary Polish language which meets all the requirements of modern science [21]. It can be used particularly by linguists, but also by computer scientists interested in natural language processing.

The NCP corpus contains over 1500 million of words. The corpus is searchable by means of advanced tools, developed by the Institute of Computer Science at the Polish Academy of Sciences, which analyse Polish inflection and Polish sentence structure. The list of sources for the NCP corpus, presented in Table 1, contains classic literature, daily newspapers, specialist periodicals and journals, transcripts of conversations, and a variety of short-lived and internet texts [22].

The results of the statistical analyses, presented in this paper, can be considered as representative for Polish language as a whole which is justified to a certain extent, considering the corpus size. However, it is worth remembering that the NCP corpus is still primarily based on written texts. Spoken language transcripts constitute a smaller percentage of the corpus contents which might be still significant when it comes to certain specialized continuous or conversational speech recognition tasks. Table 2 presents the details of the orthographic language corpus content, obtained from the NCP corpus resources.

\section{Phonemic language corpus}

\section{Grapheme-to-phoneme conversion}

The phonemic Polish language corpus contains words written with the use of phonemic notation, obtained on

Table 1 Structure of the NCP coprus [20]

\begin{tabular}{lr}
\hline Type of a text source & Percentage of the NCP corpus size \\
\hline Daily newspapers & $50.0 \%$ \\
Classic literature & $16.0 \%$ \\
Non-fiction literature & $5.5 \%$ \\
Specialized periodicals and journals & $5.5 \%$ \\
Scientific and educational texts & $2.0 \%$ \\
Other written texts & $3.0 \%$ \\
Other books & $1.0 \%$ \\
Transcripts of conversations & $10.0 \%$ \\
Internet texts & $7.0 \%$ \\
\hline
\end{tabular}

Table 2 Details of the orthographic language corpus content

\begin{tabular}{llrr}
\hline No. & Component type & $\begin{array}{r}\text { No. of unique } \\
\text { components }\end{array}$ & $\begin{array}{r}\text { No. of components } \\
\text { in the corpus }\end{array}$ \\
\hline 1 & single words & $1,943,462$ & $230,301,313$ \\
2 & 2-word sequences & $75,395,184$ & $246,110,034$ \\
3 & 3-word sequences & $170,180,746$ & $246,066,692$ \\
4 & 4-word sequences & $217,586,930$ & $246,023,356$ \\
5 & 5-word sequences & $232,439,967$ & $245,980,021$ \\
\hline
\end{tabular}

the basis of automatic grapheme-to-phoneme conversion of an orthographic text. Automatic processing of a natural language, very often requires the implementation of automatic grapheme-to-phoneme conversion. Grapheme-tophoneme conversion determines phonemic transcriptions directly from orthographic representations [23].

Phonemes are usually written with specially designed alphabets. The most commonly used alphabet for this purpose is the International Phonetic Alphabet (IPA) [24]. It was created on the basis of phonetics and phonology of West-European languages, and it is not satisfactorily adapted into Polish. For Polish, like other Slavic languages, a special transcriptional system, called the Slavistic Phonetic Alphabet (SPA), is most frequently used [25]. The second very often used phonetic alphabet is the Speech Assessment Methods Phonetic Alphabet (SAMPA) [26]. SAMPA is a machine-readable phonetic alphabet, using 7bit printable ASCII characters, based on the IPA alphabet. Table 3 presents a set of Polish phonemes and the examples of their occurrence in Polish, written with the use of the SPA, IPA, and SAMPA phonetic alphabets.

Knowledge-based grapheme-to-phoneme approaches, unlike data-driven G2P approaches, exploit rules, created by humans or deriving from linguistic studies to convert the sequence of graphemes in a word to a sequence of phonemes [27]. Rule-based grapheme-to-phoneme approaches are typically formulated in the framework of finite state automata, and require the formulation of grapheme-to-phoneme conversion rules [28]. The largest contribution to solve the problem of automatic graphemeto-phoneme conversion for Polish, were the publications of Maria Steffen-Batóg [29, 30].

Automatic grapheme-to-phoneme conversion process can be described as an $F$ function, defined by the following formula:

$$
F(\alpha)=\beta
$$

where:

$$
\begin{aligned}
& \alpha=\alpha_{1} \ldots \alpha_{k} \ldots \alpha_{a} \wedge \alpha_{k} \in X \forall(1 \leq k \leq a) \\
& \beta=\beta_{1} \ldots \beta_{k} \ldots \beta_{b} \wedge \beta_{k} \in Y \forall(1 \leq k \leq b)
\end{aligned}
$$

and where $a$ is the length of orthographic character sequence, $b$ is the length of phonemic character sequence, 
Table 3 A set of Polish phonemes and examples of their occurrence

\begin{tabular}{|c|c|c|c|c|}
\hline \multirow[b]{2}{*}{ No. } & \multicolumn{3}{|c|}{ Phonetic alphabet symbols } & \multirow[t]{2}{*}{ Example of occurrence in Polish } \\
\hline & {$[\mathrm{SPA}]$} & {$[\mathrm{IPA}]$} & [SAMPA] & \\
\hline 1 & {$[\mathrm{e}]$} & {$[\varepsilon]$} & [e] & serce \\
\hline 2 & [a] & {$[a]$} & [a] & baba \\
\hline 3 & {$[\mathrm{o}]$} & [э] & {$[0]$} & oko \\
\hline 4 & {$[\mathrm{t}]$} & {$[t]$} & {$[t]$} & trawa \\
\hline 5 & {$[\mathrm{n}]$} & {$[\mathrm{n}]$} & {$[\mathrm{n}]$} & noc \\
\hline 6 & {$[y]$} & [i] & {$[\mathrm{I}]$} & syty \\
\hline 7 & [i] & [j] & {$[j]$} & jajo \\
\hline 8 & [i] & [i] & [i] & wici \\
\hline 9 & {$[r]$} & {$[r]$} & {$[r]$} & rok \\
\hline 10 & {$[s]$} & {$[s]$} & {$[\mathrm{s}]$} & sok \\
\hline 11 & {$[v]$} & {$[v]$} & {$[\mathrm{v}]$} & wada \\
\hline 12 & {$[\mathrm{p}]$} & {$[\mathrm{p}]$} & [p] & praca \\
\hline 13 & {$[u]$} & {$[u]$} & {$[u]$} & buk \\
\hline 14 & {$[\mathrm{~m}]$} & {$[\mathrm{m}]$} & {$[\mathrm{m}]$} & mama \\
\hline 15 & {$[\mathrm{k}]$} & {$[\mathrm{k}]$} & {$[\mathrm{k}]$} & kot \\
\hline 16 & [ń] & {$[\mathrm{n}]$} & {$\left[\mathrm{n}^{\prime}\right]$} & koń \\
\hline 17 & {$[d]$} & {$[\mathrm{d}]$} & {$[d]$} & dudek \\
\hline 18 & {$[1]$} & {$[1]$} & [1] & lato \\
\hline 19 & {$[\mathrm{H}]$} & {$[\mathrm{w}]$} & {$[\mathrm{w}]$} & łysy \\
\hline 20 & [š] & {$[$ [f] } & {$[S]$} & szyszka \\
\hline 21 & {$[f]$} & {$[f]$} & {$[f]$} & fala \\
\hline 22 & [z] & {$[z]$} & {$[z]$} & koza \\
\hline 23 & {$[c]$} & {$[\widehat{\mathrm{ts}}]$} & {$[t s]$} & cacko \\
\hline 24 & {$[b]$} & {$[b]$} & [b] & baba \\
\hline 25 & {$[g]$} & [g] & [g] & godło \\
\hline 26 & [ś] & {$[6]$} & {$\left[\mathrm{s}^{\prime}\right]$} & siano \\
\hline 27 & [ć] & {$\left[\overline{t 6}_{6}\right]$} & {$\left[t s^{\prime}\right]$} & ciasto \\
\hline 28 & [x́] & [j] & {$[\mathrm{x}]$} & higiena \\
\hline 29 & [č] & {$[\widehat{t g}]$} & {$[t s]$} & czarny \\
\hline 30 & {$[z ̌]$} & {$[3]$} & {$[Z]$} & każdy \\
\hline 31 & {$[\mathrm{y}]$} & {$[\mathrm{y}]$} & {$[e \sim]$} & ręka \\
\hline 32 & {$[k]$} & {$[c]$} & {$\left[\mathrm{k}^{\prime}\right]$} & kino \\
\hline 33 & [3́] & {$[\widehat{d}]$} & {$\left[d z^{\prime}\right]$} & dziedzic \\
\hline 34 & [3] & {$[\widehat{d}]$} & {$[d z]$} & nadzy \\
\hline 35 & [ź] & {$[z]$} & {$\left[z^{\prime}\right]$} & ziarno \\
\hline 36 & [ǵ] & [J] & {$\left[g^{\prime}\right]$} & magiczny \\
\hline 37 & [̌̌] & {$[\widehat{\sigma}]$} & {$[d z]$} & drożdże \\
\hline
\end{tabular}

$X$ is the set of the orthographical alphabet characters in Polish, additionally with special characters, and $Y$ is the set of the phonemic characters alphabet in Polish, described by the Slavistic Phonetic Alphabet:

$$
\begin{aligned}
& X=\{a, a ̨, b, c, c ́ c, d, e, e ̨, f, g, h, i, j, k, l, ł, m, \\
& \text { n, ń, o, ó, p, r, s, ś, t, u, w, y, z, ź, ż, q, v, x, } \\
& ., ?, !,,,,:, ;,-,(,), \#, /\} \\
& Y=\{\mathrm{i}, \mathrm{y}, \mathrm{e}, \mathrm{a}, \mathrm{o}, \mathrm{u}, \mathrm{i}, \mathrm{u}, \mathrm{r}, \mathrm{l}, \mathrm{m}, \mathrm{n}, \mathrm{n}, \\
& \text { y, f, v, s, z, š, ž, ś, ź, } \chi, p, b, t \text {, } \\
& \text { d, k, g, ḱ, ǵ, c, z, č, ̌̌ , ć, ’́\} }
\end{aligned}
$$

Grapheme-to-phoneme conversion of correctly written orthographic texts in Polish is transformation of words written in the orthographic $X$ alphabet to form written in the phonemic alphabet $Y$. Automatic grapheme-tophoneme conversion $F$ function can be delineated by a set of formal grapheme-to-phoneme conversion rules defining how each $\alpha$ word, constructed from the orthographic $X$ alphabet, can be transformed into a new $\beta$ word constructed from the phonemic alphabet defined by the $Y$ set. The rules usually are numerous with varying degrees of complexity. The size and complexity of grapheme-tophoneme conversion rules depend on the number of letters in the orthographical alphabet and the fact that each letter can be pronounced differently in various contexts.

A set of grapheme-to-phoneme conversion rules for Polish was developed by Maria Steffen-Batóg and it was presented in the monograph dedicated to the automatic grapheme-to-phoneme conversion of texts in Polish $[29,30]$. Knowledge included into these monographs was essential in developing implementation of the automatic grapheme-to-phoneme conversion algorithm for Polish. According to Maria Steffen-Batóg, all grapheme-tophoneme conversion rules, relating to one orthographic letter, can be stored in one table, called grapheme-tophoneme conversion rules table for one letter.

According to the grapheme-to-phoneme conversion rules for Polish, described in the literature [29-32], the grapheme-to-phoneme conversion for Polish has been implemented in the Python programming language, as automatic grapheme-to-phoneme conversion application named TransFon [33]. The implementation includes 975 grapheme-to-phoneme conversion rules for 35 orthographic letters in Polish, additionally conversion rules for special characters and automatic grapheme-tophoneme conversion algorithm [33]. Block diagram of the grapheme-to-phoneme conversion algorithm for a single orthographic word is presented in Fig. 1. Due to that, many words have multiple variants of the correct pronunciation and the implementation includes only the most common basic variant of the pronunciation. Implementation of additional pronunciation variants is planned in 


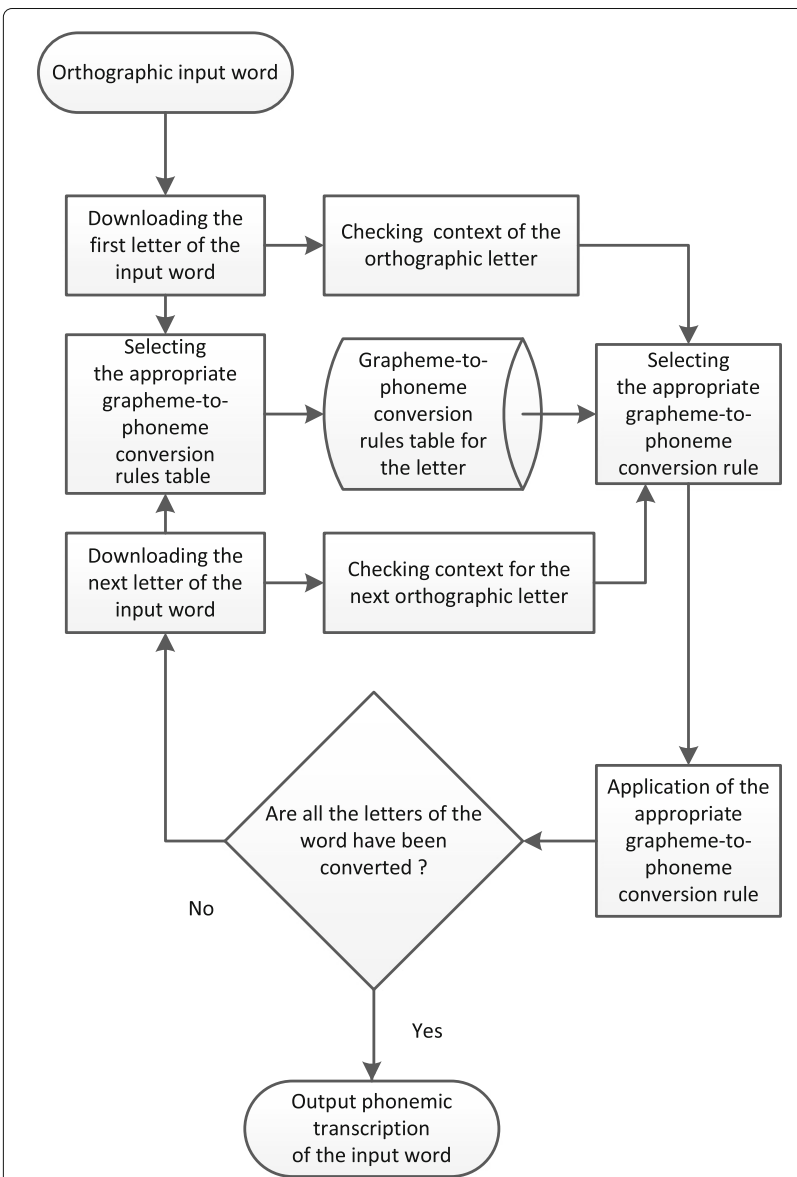

Fig. 1 Block diagram of the grapheme-to-phoneme conversion algorithm for a single orthographic word

the future. The problem of foreign words and acronyms phonemic transcription have been solved by using the dictionary where phonemic transcription of foreign words and acronyms have been defined.

TransFon application was developed entirely, without adapting any existing similar tools. The developed grapheme-to-phoneme conversion implementation is not the only one for Polish language [34-38], but only the one of them is available for free use [38]. The implementation of grapheme-to-phoneme conversion allows to apply it to any task (e.g., phonemic language corpus development for Polish).

Table 4 presents the phonemic transcription examples in Polish, written with the use of the SPA, IPA, and SAMPA phonetic alphabets $[25,26]$.

The TransFon application enables to create the phonemic language corpus only on the basis of the orthographic source corpus. After automatic grapheme-to-phoneme conversion of the orthographic corpus with the use TransFon application, phonemic language corpus for Polish was obtained, in order to perform statistical analysis of Polish language.

\section{Evaluation of grapheme-to-phoneme conversion implementation}

The evaluation of the automatic grapheme-to-phoneme conversion implementation is crucial. During implementation of automatic grapheme-to-phoneme conversion for Polish, it was necessary to check and to prove if it works properly.

The test procedure for automatic grapheme-to-phoneme conversion implementation consisted of:

- Performing the test automatic grapheme-to-phoneme conversion of orthographic text corpus file containing the most frequently used 1,943,462 unique words in Polish, obtained from the National Corpus of Polish resources [20].

- In case of doubt, validation and verification of automatic grapheme-to-phoneme conversion results for words with the use of Polish language dictionary available online, with specifying correct pronunciation of words in Polish [39].

- Registering cases of incorrect automatic grapheme-tophoneme conversion, conversion errors and other encountered problems.

The automatic phonemic transcription application was implemented in such way, that the conversion algorithm was stopped, if grapheme-to-phoneme conversion problem occurred (e.g., when there was no rule allowing for a correct phonemic transcription). This solution makes it easier to work on improving and developing the automatic grapheme-to-phoneme conversion application. In addition, any doubts about the correct pronunciation was solved with help of wiktionary.org service [39]. This solution obviously has some serious limitations. The dictionary of wiktionary.org service contains only 61,141 Polish words and only in their basic form. The verification was further complicated by other problems such as different variants of the correct pronunciation of words or pronunciation of foreign words in the corpus.

The causes of problems and errors in automatic grapheme-to-phoneme conversion operation were as follows:

- errors in the implementation of the grapheme-to-phoneme conversion algorithm and conversion rules,

- missing grapheme-to-phoneme conversion rules in the tables (i.e., rules not included in the tables) for some orthographic letters contexts,

- grapheme-to-phoneme conversion issue of foreign words, acronyms and words, which are not present in Polish language dictionary.

The above problems were solved in the following way: 
Table 4 Phonemic transcription examples in Polish

\begin{tabular}{|c|c|c|c|c|}
\hline No. & Orthographic text & $\begin{array}{c}\text { Phonemic transcription } \\
\text { [SPA] }\end{array}$ & $\begin{array}{c}\text { Phonemic transcription } \\
\text { [IPA] }\end{array}$ & $\begin{array}{c}\text { Phonemic transcription } \\
\text { [SAMPA] }\end{array}$ \\
\hline 1 & ząb & [zomp] & [zomp] & [zomp] \\
\hline 2 & ślub & [ślup] & [ślup] & [s'lup] \\
\hline 3 & wkręty & [fkrenty] & [fkrenty] & [fkrentI] \\
\hline 4 & bieżnia & [biežňa] & [bjezna] & [bjeZn'a] \\
\hline 5 & wszystkie & [fšystḱe] & {$\left[\mathrm{f} \mathfrak{\int} \dot{\mathrm{s} t c} \mathrm{C}\right]$} & [fSIstk'e] \\
\hline 6 & natomiast & [natomiast] & [natomjast] & [natomjast] \\
\hline 7 & przypadku & [pšypatku] & 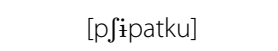 & [psIpatku] \\
\hline 8 & najbardziej & [naibarźei] & 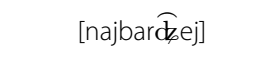 & [najbardz'ej] \\
\hline 9 & oczywiście & [očyviśće] & 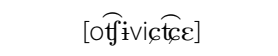 & [otsIvis'ts'e] \\
\hline 10 & powiedział & [povieźau] & [povjed্daw] & [povjedz'aw] \\
\hline
\end{tabular}

- The errors in the implementation of the grapheme-to-phoneme conversion algorithm and in conversion rules tables have been corrected by modifications, made within an application source code in Python programming language.

- The problem of missing grapheme-to-phoneme conversion rules in tables has been solved by adding new conversion rules to the existing tables. In order to complete the missing grapheme-to-phoneme conversion rules, new conversion rules were supplemented for the following orthographic letters "i", "n", "d", "z", "z", "c", "f", "s", in some contexts.

- The problems of foreign words and acronyms, have been solved by using the dictionary, where phonemic transcription of foreign words and acronyms have been defined. As a result, rule-based automatic grapheme-to-phoneme conversion was complemented by dictionary-based automatic grapheme-to-phoneme conversion method.

A number of improvements made it possible to increase effectiveness of the grapheme-to-phoneme conversion implementation. Tables 5 and 6 present the word error

Table 5 WER values of the developed G2P conversion implementation, before improvements

\begin{tabular}{llr}
\hline No. & Parameter & Value \\
\hline 1 & No. of checked unique words & $1,943,462$ \\
2 & No. of G2P conversion errors for unique words & 33,638 \\
3 & WER value for unique words in \% & 1.731 \\
4 & No. of words in the corpus & $230,301,313$ \\
5 & No. of G2P conversion errors for words in corpus & $3,707,890$ \\
6 & WER value for corpus in \% & 1.610 \\
\hline
\end{tabular}

rate (WER) values of grapheme-to-phoneme conversion implementation, before and after improvements.

The WER value for 1,943,462 checked unique words, was equal $0.387 \%$. The WER value for corpus contains $230,301,313$ words, was equal $0.030 \%$. The changes of WER values, before and after improvements, testify to the fact that implemented modifications have contributed to improving the effectiveness of G2P conversion.

\section{The developed phonemic language corpus for Polish}

The phonemic language corpus for Polish was developed by automatic grapheme-to-phoneme conversion of the source orthographic language corpus file obtained from the NCP corpus resources.

Table 7 presents the details of the phonemic language corpus content.

The phonemic language corpus contains the list of 1,943, 462 Polish words written orthographically, their phonemic transcription written with the SAMPA phonemic alphabet and additionally, the number of word occurrence in the NCP balanced corpus. The measure of the NCP balanced corpus size is the sum of all numbers of the word occurrences, which is equal to $230,301,313$ words.

Table 6 WER values of the developed G2P conversion implementation, after improvements

\begin{tabular}{llr}
\hline No. & Parameter & Value \\
\hline 1 & No. of checked unique words & $1,943,462$ \\
2 & No. of G2P conversion errors for unique words & 7525 \\
3 & WER value for unique words in \% & 0.387 \\
4 & No. of words in the corpus & $230,301,313$ \\
5 & No. of G2P conversion errors for words in corpus & 69,802 \\
6 & WER value for words in the corpus in \% & 0.030 \\
\hline
\end{tabular}


Table 7 Details of the phonemic language corpus content

\begin{tabular}{llrr}
\hline No. & Component type & $\begin{array}{r}\text { No. of unique } \\
\text { components }\end{array}$ & $\begin{array}{r}\text { No. of components } \\
\text { in the corpus }\end{array}$ \\
\hline 1 & single phonemes & 37 & $1,263,248,497$ \\
2 & 2-phoneme sequences & 1096 & $1,032,922,921$ \\
3 & 3-phoneme sequences & 17,340 & $823,393,519$ \\
4 & 4-phoneme sequences & 128,766 & $644,597,673$ \\
5 & 5-phoneme sequences & 402,529 & $483,987,550$ \\
\hline
\end{tabular}

A sample section of the developed phonemic language corpus for Polish is presented in Table 8. It should also be noted that the standard SAMPA for Polish includes several sequences of phonemic transcription labels that may cause ambiguity unless separated by spaces or other characters. To avoid this problem, all phonemes are separated by square brackets.

\section{Analysis of the obtained results and discussion Statistical analysis of the orthographic and phonemic language corpora}

With the use of the orthographic and phonemic language corpora, it was possible to perform statistical analysis of Polish language which includes calculation of the following distributions:

- the frequency of the single orthographic word occurrence,

- the frequency of the $n$-word sequence occurrence for $n=2, \ldots, 5$,

- the frequency of the phoneme occurrence,

- the frequency of the $n$-phoneme sequence occurrence for $n=2, \ldots, 5$.

The frequency distribution of words in the orthographic language corpus, is presented in Fig. 2.

A sample calculated frequency of word occurrence, is presented in Table 9, where $1 \%$ corresponds to about 2303013 occurrences.

A sample calculated frequency of occurrence for the two-word and the three-word sequences, are presented in Tables 10 and 11. The results for the four-word and the five-word sequences, are not presented in this paper, but they can also be helpful to develop advanced word-based language models.

The frequency distribution of the phonemes in the phonemic language corpus, is presented in Fig. 3.

The frequency distributions of the $n$-phoneme sequences, for $n=2, \ldots, 5$, are presented in Fig. 4 .

\section{Evaluation of the obtained results}

The results of the research on statistical analysis of Polish language, performed with the phonemic language corpus, were compared to other results published in the literature
Table 8 A sample section of the developed phonemic language corpus for Polish

\begin{tabular}{|c|c|c|c|}
\hline & $\begin{array}{r}\text { Number of occurr. } \\
\text { of } 230301313\end{array}$ & Orthographic word & $\begin{array}{l}\text { Phonemic transcription } \\
\text { of word }\end{array}$ \\
\hline$i$ & $C\left(w_{i}\right)$ & $w_{i}$ & [SAMPA] \\
\hline 1 & $7,692,997$ & w & {$[f]$} \\
\hline 2 & $5,333,210$ & i & [i] \\
\hline 3 & $4,235,003$ & na & {$[\mathrm{n}][\mathrm{a}]$} \\
\hline 4 & $4,158,902$ & z & {$[\mathrm{s}]$} \\
\hline 5 & $3,981,525$ & się & {$\left[s^{\prime}\right][e]$} \\
\hline 6 & $3,601,719$ & nie & {$\left[n^{\prime}\right][e]$} \\
\hline 7 & $2,904,114$ & do & {$[\mathrm{d}][0]$} \\
\hline 8 & $2,205,896$ & że & {$[z][e]$} \\
\hline 9 & $2,171,877$ & to & {$[t][0]$} \\
\hline 10 & $1,731,304$ & O & {$[\circ]$} \\
\hline 11 & $1,728,527$ & jest & {$[j][e][s][t]$} \\
\hline 12 & $1,425,793$ & a & [a] \\
\hline 13 & $1,003,027$ & jak & {$[j][a][k]$} \\
\hline 14 & 983,395 & po & [p] [o] \\
\hline 15 & 912,660 & od & {$[0][t]$} \\
\hline 16 & 877,522 & ale & {$[a][1][e]$} \\
\hline 17 & 847,373 & za & {$[z][a]$} \\
\hline 18 & 775,006 & przez & {$[\mathrm{p}][\mathrm{S}][\mathrm{e}][\mathrm{s}]$} \\
\hline 19 & 754,024 & co & {$[t s][0]$} \\
\hline 20 & 663,771 & dla & [d] [1] [a] \\
\hline 21 & 645,573 & czy & {$[t S][I]$} \\
\hline 22 & 610,035 & tym & {$[t][I][m]$} \\
\hline 23 & 607,673 & już & {$[j][u][s]$} \\
\hline 24 & 544,343 & tak & {$[t][a][k]$} \\
\hline 25 & 534,509 & tylko & {$[\mathrm{t}][\mathrm{I}][\mathrm{I}][\mathrm{k}][\mathrm{o}]$} \\
\hline 26 & 500,801 & ma & {$[\mathrm{m}][\mathrm{a}]$} \\
\hline 27 & 475,172 & może & {$[\mathrm{m}][\mathrm{o}][\mathrm{z}][\mathrm{e}]$} \\
\hline 28 & 451,225 & tego & {$[t][e][g][o]$} \\
\hline 29 & 445,705 & ze & {$[z][e]$} \\
\hline 30 & 426,201 & jego & {$[j][e][g][o]$} \\
\hline$\ldots$ & $\ldots$ & $\ldots$ & \\
\hline
\end{tabular}

[40-46]. Summary comparisons of the obtained statistical language data, to other results, available in the literature, are presented in Tables:

- Table 12 presents the occurrence frequency of Polish phonemes and comparison to the results published in the literature [40, 42, 44, 45],

- Table 13 presents the occurrence frequency of the two-phoneme sequences (diphones) in Polish and comparison to the results published in the literature [45], 


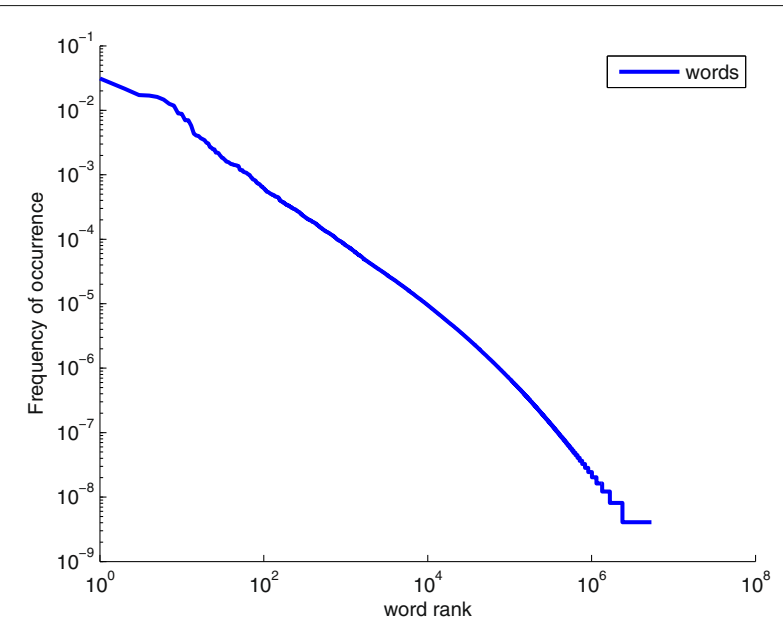

Fig. 2 Frequency distribution of the word occurrence in Polish language

- Table 14 presents the occurrence frequency of the three-phoneme sequences (triphones) in Polish and comparison to the results published in the literature [45].

The reasons of differences among the obtained results of the language statistical analysis performed by other scientists may be: differences in used corpora (e.g., in size, quality, linguistic structure) and development of language and changes over time. Language is constantly changing, evolving, and adapting to the needs of its speakers. All languages change continually, and do so in many and varied ways (e.g., lexical changes, phonetic and phonological changes, spelling changes, semantic and syntactic changes) [47]. Therefore, a results of research performed using different corpora may be very different from each other $[48,49]$. The most similar results apply statistical analysis of Polish phonemes occurrence presented in Table $12[44,45]$. The least accurate results were obtained with much smaller language corpus a few decades ago [40-42]. Taking into account the results, available in the literature, it can be concluded that performed statistical analysis of Polish language, was extensive. No results of a statistical analysis of the $n$-phoneme sequences occurrence in Polish for $n>3$ were found in the literature. On the basis of the comparison results, the following conclusion can be drawn: The developed phonemic language corpus in Polish, which was used to perform statistical analysis of Polish language, was very huge, containing 1263248497 phonemes, but not the biggest developed for Polish language [44]. The statistical analysis results obtained based on it, allow to develop statistical models of Polish language.
Table 9 Frequency of the word occurrence in the orthographic corpus file

\begin{tabular}{|c|c|c|}
\hline No. & Frequency of occurrence & Word \\
\hline$i$ & $f\left(w_{i}\right) \cdot 100[\%]$ & $w_{i}$ \\
\hline 1 & 3.34041 & w \\
\hline 2 & 2.31575 & i \\
\hline 3 & 1.83890 & na \\
\hline 4 & 1.80585 & z \\
\hline 5 & 1.72883 & się \\
\hline 6 & 1.56392 & nie \\
\hline 7 & 1.26101 & do \\
\hline 8 & 0.95783 & że \\
\hline 9 & 0.94306 & to \\
\hline 10 & 0.75176 & O \\
\hline 11 & 0.75055 & jest \\
\hline 12 & 0.61910 & a \\
\hline 13 & 0.43553 & jak \\
\hline 14 & 0.42700 & po \\
\hline 15 & 0.39629 & od \\
\hline 16 & 0.38103 & ale \\
\hline 17 & 0.36794 & za \\
\hline 18 & 0.33652 & przez \\
\hline 19 & 0.32741 & co \\
\hline 20 & 0.28822 & dla \\
\hline 21 & 0.28032 & czy \\
\hline 22 & 0.26489 & tym \\
\hline 23 & 0.26386 & już \\
\hline 24 & 0.23640 & są \\
\hline 25 & 0.23636 & tak \\
\hline 26 & 0.23209 & tylko \\
\hline 27 & 0.21745 & ma \\
\hline 28 & 0.20633 & może \\
\hline 29 & 0.19593 & tego \\
\hline 30 & 0.19353 & ze \\
\hline$\ldots$ & $\ldots$ & $\ldots$ \\
\hline
\end{tabular}

\section{Frequency of the word occurrence}

The frequency of word occurrence in a language is well described by Zipf's law [50, 51]:

$$
Z_{r}=\frac{a}{r^{b}}
$$

where $Z_{r}$ is the frequency of the word ranked $r$, where $r$ is the rank of the word if frequencies are ranked from the most frequent $(r=1)$ to the least frequent $(r=n)$, and $a$ and $b$ are parameters to be estimated from obtained statistical data. The usual findings is that $b$ is close to 1 [50]. The fit of Zipf's equation to the ranked frequency distribution of Polish words is presented in Fig. 5. 
Table 10 Frequency of the two-word sequence occurrence in the orthographic corpus file

\begin{tabular}{|c|c|c|}
\hline No. & $\begin{array}{l}\text { Frequency of occurrence } \\
f\left(w_{i-1}, w_{i}\right) \cdot 100[\%]\end{array}$ & $\begin{array}{l}\text { 2-word sequence } \\
w_{i-1} w_{i}\end{array}$ \\
\hline 1 & 0.12643 & się w \\
\hline 2 & 0.10243 & w tym \\
\hline 3 & 0.08805 & się na \\
\hline 4 & 0.08287 & się z \\
\hline 5 & 0.07604 & się do \\
\hline 6 & 0.06529 & nie ma \\
\hline 7 & 0.05799 & nie jest \\
\hline 8 & 0.05597 & się, że \\
\hline 9 & 0.04932 & w tej \\
\hline 10 & 0.04741 & jest to \\
\hline 11 & 0.04602 & że w \\
\hline 12 & 0.04595 & że nie \\
\hline 13 & 0.04209 & iw \\
\hline 14 & 0.04209 & nie tylko \\
\hline 15 & 0.04118 & to nie \\
\hline 16 & 0.04083 & inie \\
\hline 17 & 0.03882 & to jest \\
\hline 18 & 0.03698 & się nie \\
\hline 19 & 0.03145 & to, że \\
\hline 20 & 0.02843 & że to \\
\hline 21 & 0.02751 & ale nie \\
\hline 22 & 0.02725 & przede wszystkim \\
\hline 23 & 0.02718 & w Polsce \\
\hline 24 & 0.02675 & $a w$ \\
\hline 25 & 0.02671 & a nie \\
\hline 26 & 0.02668 & jest w \\
\hline 27 & 0.02640 & po prostu \\
\hline 28 & 0.02629 & w którym \\
\hline 29 & 0.02599 & jak i \\
\hline 30 & 0.02543 & nie było \\
\hline$\cdots$ & $\cdots$ & $\cdots$ \\
\hline
\end{tabular}

The ranked frequency distribution of Polish words was estimated by Zipf's equation in the following form:

$$
Z_{r}=\frac{0.041566}{r^{0.9}}
$$

The average fit of Zipf's equation to the ranked frequency distribution of Polish words was measured by the coefficient of determination $R^{2}$ value. The coefficient of determination for fit of Zipf's equation, presented in Equation (7), to the ranked frequency distribution of Polish words is equal:

$$
R^{2}=0.90729
$$

Table 11 Frequency of the three-word sequence occurrence in

\begin{tabular}{|c|c|c|}
\hline No. & $\begin{array}{l}\text { Frequency of occurrence } \\
f\left(w_{i-2}, w_{i-1}, w_{i}\right) \cdot 100[\%]\end{array}$ & $\begin{array}{l}3 \text {-word sequence } \\
w_{i-2} w_{i-1} w_{i}\end{array}$ \\
\hline 1 & 0.01890 & w związku z \\
\hline 2 & 0.01325 & w tym roku \\
\hline 3 & 0.01238 & ze względu na \\
\hline 4 & 0.01195 & w ten sposób \\
\hline 5 & 0.00921 & na to, że \\
\hline 6 & 0.00920 & okazało się, że \\
\hline 7 & 0.00915 & w tej chwili \\
\hline 8 & 0.00902 & o tym, że \\
\hline 9 & 0.00892 & po raz pierwszy \\
\hline 10 & 0.00891 & w stosunku do \\
\hline 11 & 0.00871 & do tej pory \\
\hline 12 & 0.00791 & w tej sprawie \\
\hline 13 & 0.00786 & jeśli chodzi o \\
\hline 14 & 0.00728 & związku z tym \\
\hline 15 & 0.00665 & to nie jest \\
\hline 16 & 0.00615 & nie jest to \\
\hline 17 & 0.00588 & o których mowa \\
\hline 18 & 0.00582 & których mowa w \\
\hline 19 & 0.00566 & że jest to \\
\hline 20 & 0.00529 & w tym czasie \\
\hline 21 & 0.00522 & w tym samym \\
\hline 22 & 0.00505 & nie moze być \\
\hline 23 & 0.00498 & w ogóle nie \\
\hline 24 & 0.00498 & mi się, że \\
\hline 25 & 0.00473 & że nie ma \\
\hline 26 & 0.00472 & nie da się \\
\hline 27 & 0.00442 & w ubiegłym roku \\
\hline 28 & 0.00440 & mam nadzieję, że \\
\hline 29 & 0.00421 & w zalezności od \\
\hline 30 & 0.00410 & na tym, że \\
\hline$\cdots$ & $\cdots$ & $\cdots$ \\
\hline
\end{tabular}
the orthographic corpus file

Additionally, root-mean-square error RMSE value was calculated for this case and it is equal:

$$
R M S E=7.6475 \cdot 10^{-6}
$$

The $R^{2}$ value indicates how well statistical data fit into a statistical model. The $R^{2}$ value equals $R^{2}=0.90729$ indicates that the Zipf's equation fits well to the obtained statistical data of the word occurrence frequency in Polish language.

On this basis and on the basis of the results available in the literature [51-53], it can be concluded that the statistical data, obtained as the result of performed statistical 


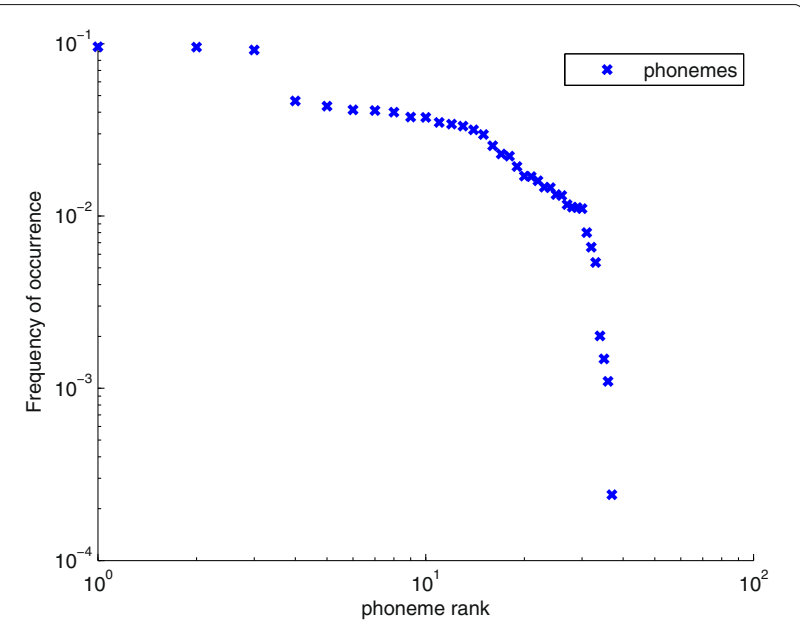

Fig. 3 Frequency distribution of the phoneme occurrence in Polish language

analysis of Polish language, based on the orthographic language corpus, are correct.

\section{Frequency of the phoneme and n-phoneme sequence occurrence}

The frequency of word occurrence in a language is well described by Zipf's law [50]. However, Zipf's law does not describe well the distribution of the phonemes and phoneme sequences out of which words are composed. The examination of occurrence frequency in 95 languages, presented in the literature [51], shows that phoneme frequencies are best described by an equation first developed by Yule, that also describes the distribution of DNA codons [54]. The frequency of the phoneme occurrence in a language is described well by Yule's equation formula [51]:

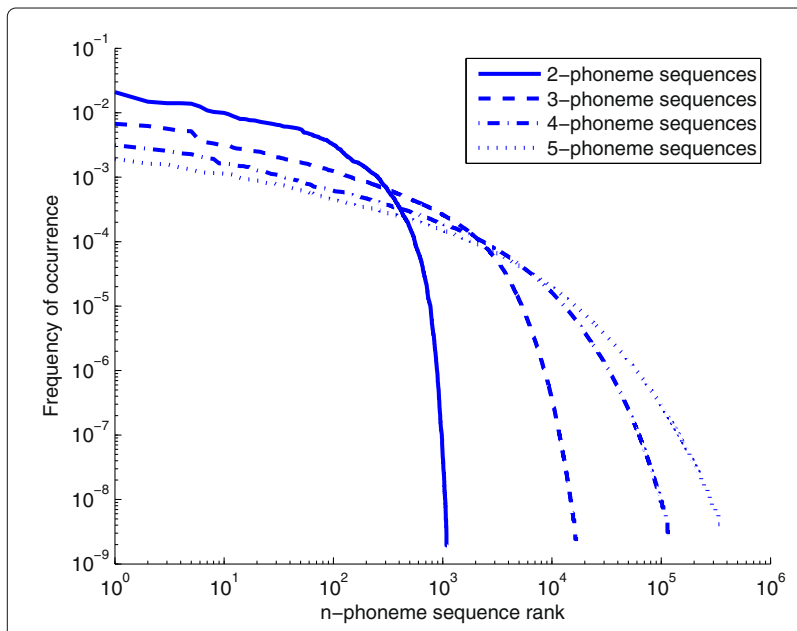

Fig. 4 Frequency distribution of the $n$-phoneme sequence occurrence in Polish language, for $n=2, \ldots, 5$

$$
Y_{r}=\frac{a}{r^{b}} \cdot c^{r}
$$

where $Y_{r}$ is the frequency of the phoneme ranked $r$, and $r$ is the rank of the phoneme if frequencies are ranked from the most frequent $(r=1)$ to the least frequent $(r=n)$, and $a, b$ and $c$ are parameters to be estimated from the obtained statistical data.

The fits of Zipf's and Yule's equations to the ranked frequency distribution of Polish phonemes are presented in Fig. 6.

The evaluation results of the fits of Zipf's and Yule's equations to the ranked frequency distribution of Polish phonemes are presented in Table 15.

Note that the Zipf's equation is a special case of the Yule's equation in which $c^{r}$ is neglected. It is not always possible to neglect this term. As shown in Fig. 6 and in Table 15, the Yule's equation fits to the distribution of the phoneme frequencies in Polish much better than the Zipf's equation. It is not an isolated case and similar regularity can be observed in other languages [51].

The same regularity was observed for frequency distributions of the $n$-phoneme sequence occurrence for Polish language, for $n=2, \ldots, 5$. The Figs. 7 and 8 present the fit of Yule's equation to the ranked frequency distribution of Polish $n$-phoneme sequences for $n=2$ and $n=3$.

The summary of evaluation results of the Yule's equation fits to the ranked frequency distribution of Polish phonemes and the $n$-phoneme sequences for $n=$ $2, \ldots, 5$ are presented in Table 16 .

The values of $R^{2}$, presented in Table 16, indicate that the Yule's equation fits very well to the obtained statistical data of frequency occurrence of Polish phonemes and the $n$-phoneme sequences for $n=2, \ldots, 5$. A similar properties are observed for other languages. On the basis of the obtained results and the results available in the literature $[40,41,43-46,51]$, it can be concluded that statistical data, obtained as the result of performed statistical analysis of Polish language, based on the orthographic and phonemic language corpora, are correct.

\section{Example of practical application of the obtained results for language modelling}

This article contains a general statistics of Polish language that can be useful for a variety of language and speech processing applications, including automatic speech recognition with language models [55].

The goal of the word-based language model, is to model the sequence of words in the context of the task, being performed by the speech recognition system. In continuous speech recognition, the incorporation of the language model is crucial to reduce the search speed of recognized words sequence $W$. The probability $P(W)$ of occurrence $W$, sequence of $n$ words $w_{i}$, can be decomposed as [17]: 
Table 12 Frequency of Polish phoneme occurrence-comparison to the results published in the literature $[40,42,44,45]$

\begin{tabular}{|c|c|c|c|c|c|c|}
\hline No. & Obtained results & Phoneme [SAMPA] & Results in [44] & Results in [45] & Results in [42] & Results in [40] \\
\hline i & $f\left(q_{i}\right)[\%]$ & {$\left[q_{i}\right]$} & $f\left(q_{i}\right)[\%]$ & $f\left(q_{i}\right)[\%]$ & $f\left(q_{i}\right)[\%]$ & $f\left(q_{i}\right)[\%]$ \\
\hline 1 & 9.59478 & {$[e]$} & 7.882 & 9.108 & 10.6 & 10.2 \\
\hline 2 & 9.55135 & [a] & 8.141 & 9.584 & 9.7 & 9.3 \\
\hline 3 & 9.20001 & [०] & 7.646 & 8.994 & 8.0 & 9.1 \\
\hline 4 & 4.65630 & {$[t]$} & 3.708 & 4.489 & 4.8 & 4.4 \\
\hline 5 & 4.34100 & {$[\mathrm{n}]$} & 3.665 & 4.443 & 4.0 & 4.0 \\
\hline 6 & 4.13142 & {$[\mathrm{I}]$} & 3.174 & 3.648 & 3.8 & 4.1 \\
\hline 7 & 4.09810 & {$[j]$} & 3.299 & 3.796 & 4.4 & 4.5 \\
\hline 8 & 4.00623 & [i] & 3.620 & 4.359 & 3.4 & 3.9 \\
\hline 9 & 3.75265 & {$[r]$} & 3.705 & 4.674 & 3.2 & 3.6 \\
\hline 10 & 3.73464 & {$[s]$} & 2.927 & 3.638 & 2.8 & 3.0 \\
\hline 11 & 3.49063 & {$[\mathrm{v}]$} & 3.137 & 3.782 & 2.9 & 3.5 \\
\hline 12 & 3.41265 & [p] & 2.759 & 3.263 & 3.0 & 3.1 \\
\hline 13 & 3.32576 & {$[u]$} & 2.774 & 3.345 & 2.8 & 3.4 \\
\hline 14 & 3.16465 & {$[\mathrm{~m}]$} & 2.626 & 2.988 & 3.2 & 3.5 \\
\hline 15 & 2.96802 & {$[\mathrm{k}]$} & 2.418 & 2.976 & 2.5 & 2.7 \\
\hline 16 & 2.55419 & {$\left[n^{\prime}\right]$} & 1.840 & 2.088 & 2.4 & 2.6 \\
\hline 17 & 2.29278 & {$[d]$} & 2.391 & 2.888 & 2.1 & 2.2 \\
\hline 18 & 2.22555 & [1] & 2.164 & 2.642 & 1.9 & 2.1 \\
\hline 19 & 1.93507 & {$[\mathrm{w}]$} & 1.626 & 1.636 & 1.8 & 2.2 \\
\hline 20 & 1.70517 & {$[S]$} & 1.118 & 1.215 & 1.9 & 2.0 \\
\hline 21 & 1.69430 & {$[f]$} & 1.363 & 1.683 & 1.3 & 1.5 \\
\hline 22 & 1.60077 & {$[z]$} & 1.665 & 1.947 & 1.5 & 1.8 \\
\hline 23 & 1.46934 & {$[t s]$} & 1.335 & 1.692 & 1.2 & 1.5 \\
\hline 24 & 1.46097 & [b] & 1.304 & 1.497 & 1.5 & 1.5 \\
\hline 25 & 1.33050 & {$[g]$} & 1.341 & 1.547 & 1.3 & 1.5 \\
\hline 26 & 1.31409 & {$\left[\mathrm{~s}^{\prime}\right]$} & 0.927 & 0.965 & 1.6 & 1.5 \\
\hline 27 & 1.16326 & {$\left[t s^{\prime}\right]$} & 0.643 & 0.662 & 1.2 & 1.3 \\
\hline 28 & 1.12532 & {$[\mathrm{x}]$} & 1.153 & 1.427 & 1.0 & 1.1 \\
\hline 29 & 1.11761 & {$[t s]$} & 0.831 & 0.955 & 1.2 & 1.2 \\
\hline 30 & 1.10377 & {$[Z]$} & 0.884 & 0.944 & 1.3 & 1.2 \\
\hline 31 & 0.79984 & {$[e \sim]$} & 0.582 & 0.673 & 0.6 & 0.7 \\
\hline 32 & 0.65927 & {$\left[\mathrm{k}^{\prime}\right]$} & 0.570 & 0.698 & 0.7 & n.a. \\
\hline 33 & 0.53682 & {$\left[d z^{\prime}\right]$} & 0.538 & 0.554 & 0.7 & 0.8 \\
\hline 34 & 0.20125 & {$[d z]$} & 0.227 & 0.261 & 0.2 & 0.2 \\
\hline 35 & 0.14815 & {$\left[z^{\prime}\right]$} & 0.183 & 0.195 & 0.2 & 0.2 \\
\hline 36 & 0.10971 & {$\left[g^{\prime}\right]$} & 0.198 & 0.260 & 0.1 & n.a. \\
\hline 37 & 0.02412 & {$[d z]$} & 0.037 & 0.040 & 0.1 & 0.0 \\
\hline
\end{tabular}

$$
P(W)=P\left(w_{1}\right) \prod_{i=2}^{n} P\left(w_{i} \mid w_{1}, \ldots, w_{i-1}\right)
$$

where $P\left(w_{i} \mid w_{1}, \ldots, w_{i-1}\right)$ is the conditional probability that $w_{i}$ will occur, given the previous word sequence $w_{1}, \ldots, w_{i-1}$. Unfortunately, it is impossible to compute the conditional word probabilities $P\left(w_{i} \mid w_{1}, \ldots, w_{i-1}\right)$ for all words and all sequence lengths in a given language. Even though the sequences are limited to moderate values of $i$, there would not be enough data to estimate reliably all of the conditional probabilities. The conditional probability can be approximated by estimating the 
Table 13 Frequency of the two-phoneme sequence occurrence in Polish—comparison to the results published in the literature [45]

\begin{tabular}{|c|c|c|c|}
\hline No. & $\begin{array}{l}\text { Obtained results } \\
f\left(q_{i-1}, q_{i}\right)[\%]\end{array}$ & $\begin{array}{l}\text { Diphone [SAMPA] } \\
{\left[q_{i-1}\right]\left[q_{i}\right]}\end{array}$ & $\begin{array}{l}\text { Results in [45] } \\
f\left(q_{i-1}, q_{i}\right)[\%]\end{array}$ \\
\hline 1 & 2.09086 & {$[j][e]$} & 1.7253 \\
\hline 2 & 1.48817 & {$[\mathrm{n}][\mathrm{a}]$} & 1.1632 \\
\hline 3 & 1.40880 & {$\left[n^{\prime}\right][e]$} & 0.8438 \\
\hline 4 & 1.40198 & {$[s][t]$} & 1.0791 \\
\hline 5 & 1.38280 & [p] [o] & 1.0479 \\
\hline 6 & 1.25078 & {$[\mathrm{o}][\mathrm{v}]$} & 1.1829 \\
\hline 7 & 1.08491 & {$[r][a]$} & 0.9189 \\
\hline 8 & 1.03023 & {$[\mathrm{o}][\mathrm{n}]$} & 0.8756 \\
\hline 9 & 1.01037 & {$[r][0]$} & 0.9155 \\
\hline 10 & 0.99573 & {$[\mathrm{v}][\mathrm{a}]$} & 0.8012 \\
\hline 11 & 0.94847 & {$[t][a]$} & 0.8035 \\
\hline 12 & 0.88593 & {$[\mathrm{k}][0]$} & 0.7337 \\
\hline 13 & 0.84639 & {$[j][a]$} & 0.6367 \\
\hline 14 & 0.79998 & {$[o][e \sim]$} & 0.506 \\
\hline 15 & 0.79985 & {$[v][j]$} & 0.442 \\
\hline 16 & 0.79298 & {$[\mathrm{~d}][0]$} & 0.6459 \\
\hline 17 & 0.76749 & {$[e][j]$} & 0.6620 \\
\hline 18 & 0.76340 & {$[\mathrm{a}][\mathrm{w}]$} & 0.5595 \\
\hline 19 & 0.75699 & {$[t][e]$} & 0.6229 \\
\hline 20 & 0.74761 & {$[t][0]$} & 0.5814 \\
\hline 21 & 0.72197 & {$[z][a]$} & 0.497 \\
\hline 22 & 0.71902 & {$[\mathrm{e}][\mathrm{m}]$} & 0.60411 \\
\hline 23 & 0.71384 & {$[\mathrm{~g}][0]$} & 0.515 \\
\hline 24 & 0.69492 & {$[\mathrm{e}][\mathrm{n}]$} & 0.6768 \\
\hline 25 & 0.68893 & {$[S][e]$} & 0.456 \\
\hline 26 & 0.68631 & {$[\mathrm{k}][\mathrm{a}]$} & 0.540 \\
\hline 27 & 0.67323 & {$[\mathrm{n}][\mathrm{e}]$} & 0.60803 \\
\hline 28 & 0.67050 & {$[\mathrm{~V}][\mathrm{I}]$} & 0.526 \\
\hline 29 & 0.66791 & [1] [i] & 0.58227 \\
\hline$\cdots$ & $\ldots$ & $\ldots$ & $\ldots$ \\
\hline
\end{tabular}

probability only on the preceding $N-1$ words defined by the following formula:

$$
P(W)=P\left(w_{1}\right) \prod_{i=1}^{n} P\left(w_{i} \mid w_{i-N+1}, \ldots, w_{i-1}\right)
$$

This approximation is commonly referred to as $\mathrm{N}$-gram model [17]. The most popular solutions published in the literature, relate to the application of $N$-gram language models for word-based speech recognition tasks [56-59].
Table 14 Frequency of the three-phoneme sequence occurrence in Polish-comparison to the results published in the literature [45]

\begin{tabular}{|c|c|c|c|}
\hline No. & $\begin{array}{l}\text { Obtained results } \\
f\left(q_{i-2}, q_{i-1}, q_{i}\right)[\%]\end{array}$ & $\begin{array}{l}\text { Triphone [SAMPA] } \\
{\left[q_{i-2}\right]\left[q_{i-1}\right]\left[q_{i}\right]}\end{array}$ & $\begin{array}{l}\text { Results in [45] } \\
f\left(q_{i-2}, q_{i-1}, q_{i}\right)[\%]\end{array}$ \\
\hline 1 & 0.67353 & {$[v][j][e]$} & 0.3159 \\
\hline 2 & 0.62188 & [e] [g] [o] & 0.3655 \\
\hline 3 & 0.56670 & {$[0][v][a]$} & 0.3801 \\
\hline 4 & 0.52262 & {$[s][t][a]$} & 0.3287 \\
\hline 5 & 0.51677 & {$[p][S][e]$} & 0.2969 \\
\hline 6 & 0.36109 & {$[m][j][e]$} & 0.2503 \\
\hline 7 & 0.34557 & {$[e][s][t]$} & 0.1734 \\
\hline 8 & 0.33317 & {$[0][n][t s]$} & 0.1749 \\
\hline 9 & 0.32041 & {$[p][r][a]$} & 0.1681 \\
\hline 10 & 0.31920 & {$[0]\left[\mathrm{s}^{\prime}\right]\left[t \mathrm{~s}^{\prime}\right]$} & 0.1533 \\
\hline 11 & 0.31277 & {$[j][0][n]$} & 0.189 \\
\hline 12 & 0.28832 & {$[j][0][e \sim]$} & 0.143 \\
\hline 13 & 0.27851 & {$[\mathrm{p}][S][I]$} & 0.118 \\
\hline 14 & 0.27638 & {$[k][t][u]$} & 0.1311 \\
\hline 15 & 0.27428 & {$[\mathrm{p}][\mathrm{r}][\mathrm{o}]$} & 0.1807 \\
\hline 16 & 0.26887 & {$[t][u][r]$} & 0.1448 \\
\hline 17 & 0.25608 & {$[\mathrm{n}][\mathrm{I}][\mathrm{x}]$} & 0.1673 \\
\hline 18 & 0.25453 & {$[0][v][j]$} & 0.1404 \\
\hline 19 & 0.25330 & {$[j][e][s]$} & n.a. \\
\hline 20 & 0.25049 & {$[0][s][t]$} & 0.1785 \\
\hline 21 & 0.24914 & {$[p][j][e]$} & 0.120 \\
\hline 22 & 0.24394 & {$[e][n][t]$} & 0.1842 \\
\hline 23 & 0.23760 & {$[a][j][0]$} & 0.126 \\
\hline 24 & 0.23674 & [a] [1] [e] & 0.116 \\
\hline 25 & 0.22874 & {$\left[s^{\prime}\right]\left[t s^{\prime}\right][i]$} & 0.130 \\
\hline 26 & 0.22739 & [p] [o] [v] & 0.122 \\
\hline 27 & 0.22454 & {$[\mathrm{a}]\left[\mathrm{n}^{\prime}\right][\mathrm{e}]$} & 0.1586 \\
\hline 28 & 0.21298 & {$[\mathrm{~s}][\mathrm{p}][\mathrm{o}]$} & 0.1627 \\
\hline 29 & 0.20990 & {$[0][v][e]$} & 0.1712 \\
\hline$\cdots$ & $\cdots$ & $\cdots$ & $\cdots$ \\
\hline
\end{tabular}

The language modelling may be based on modelling of words, as well as sub-words (e.g. phonemes). Statistical analysis of the phonemic corpus enables to develop statistical language models, based on phonemes.

For sequence of the phonemes $Q=q_{1} \ldots q_{m}$, containing $m$ phonemes $q_{i}$, the probability $P(Q)$ is given by a phoneme-based language model and the following formula:

$$
P(Q)=P\left(q_{1}\right) \prod_{i=2}^{m} P\left(q_{i} \mid q_{1}, \ldots, q_{i-1}\right)
$$




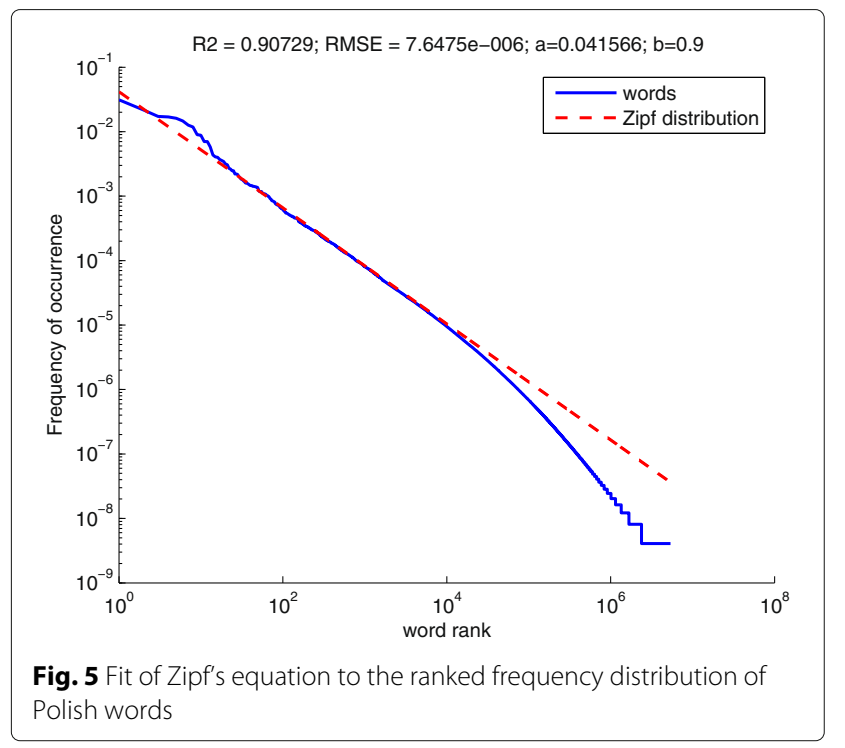

where $P\left(q_{i} \mid q_{1}, \ldots, q_{i-1}\right)$ is the conditional probability that $q_{i}$ will occur, given the previous phoneme sequence $q_{1}, \ldots, q_{i-1}$. The $P(Q)$ probability approximation for $N$-gram phoneme-based language model is defined by the analogous formula:

$$
P(Q)=P\left(q_{1}\right) \prod_{i=2}^{m} P\left(q_{i} \mid q_{i-N+1}, \ldots, q_{i-1}\right)
$$

On the basis of performed statistical analysis of the orthographic language corpus, there have been developed the $N$-gram word-based language models for $N=$ $1, \ldots, 3$, intended for Polish language. In a similar way, on the basis of statistical analysis results of the phonemic language corpus, the $N$-gram phoneme-based language models for $N=1, \ldots, 3$, intended for Polish language,

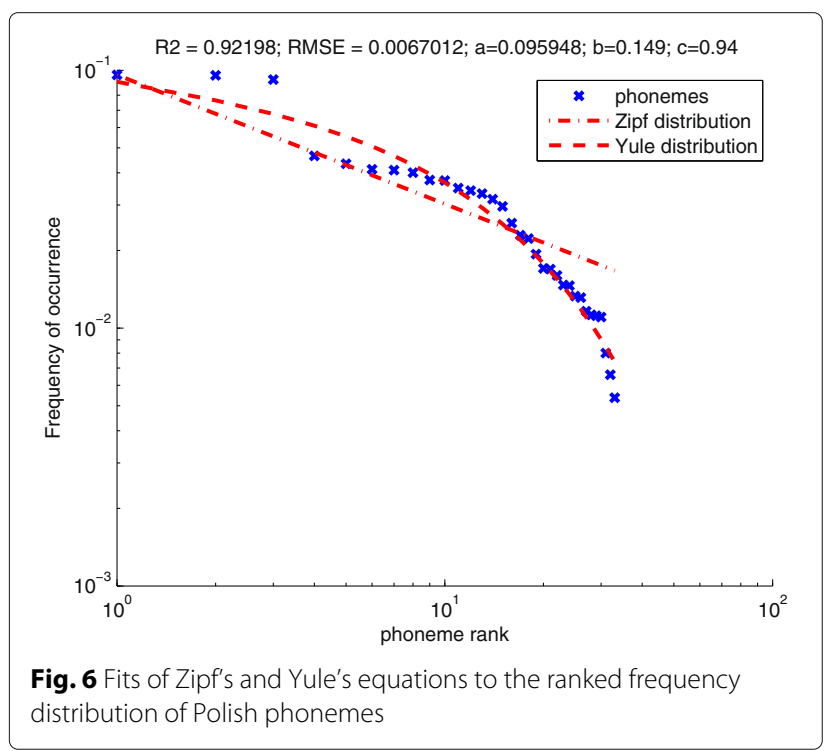

Table 15 Evaluation results of the fits of Zipf's and Yule's equations to the ranked frequency distribution of Polish phonemes

\begin{tabular}{llll}
\hline No. & Equation & $R^{2}$ & RMSE \\
\hline 1 & $Z_{r}=\frac{0.095948}{r^{0.5}}$ & 0.81180 & $1.0408 \cdot 10^{-2}$ \\
2 & $Y_{r}=\frac{0.095948}{r^{0.149}} \cdot 0.94^{r}$ & 0.92198 & $6.7012 \cdot 10^{-3}$ \\
\hline
\end{tabular}

were developed. The details of word-based and phonemebased language models developing process are presented in the separate publication. This article presents only the example of language statistical analysis application to develop selected language models.

An approach to evaluate a language model is word recognition error rate [60].

However, this approach requires a working speech recognition system. Alternatively, we can measure the average number of possible words that follow any given word sequence in a language. This is the derivative measure of entropy, known as perplexity (PP) [17]. Given a language model $P(W)$, where $W$ is the $n$-word sequence, the entropy of the language model can be defined as [61]:

$$
H(W)=-\frac{1}{n} \log _{2}(P(W))
$$

For $N$-gram language model, $H(W)$ entropy can be calculated with the following formula:

$$
H(W)=-\frac{1}{n} \sum_{i=1}^{n} \log _{2}\left(P\left(w_{i} \mid w_{i-N+1}, \ldots, w_{i-1}\right)\right)
$$

Note that as $n$ approaches infinity, the entropy approaches the asymptotic entropy of the source defined by the measure $P(W)$. This means that the typical length of the sequence must approach infinity, which is of course impossible. Thus, entropy $H(W)$ should be estimated on

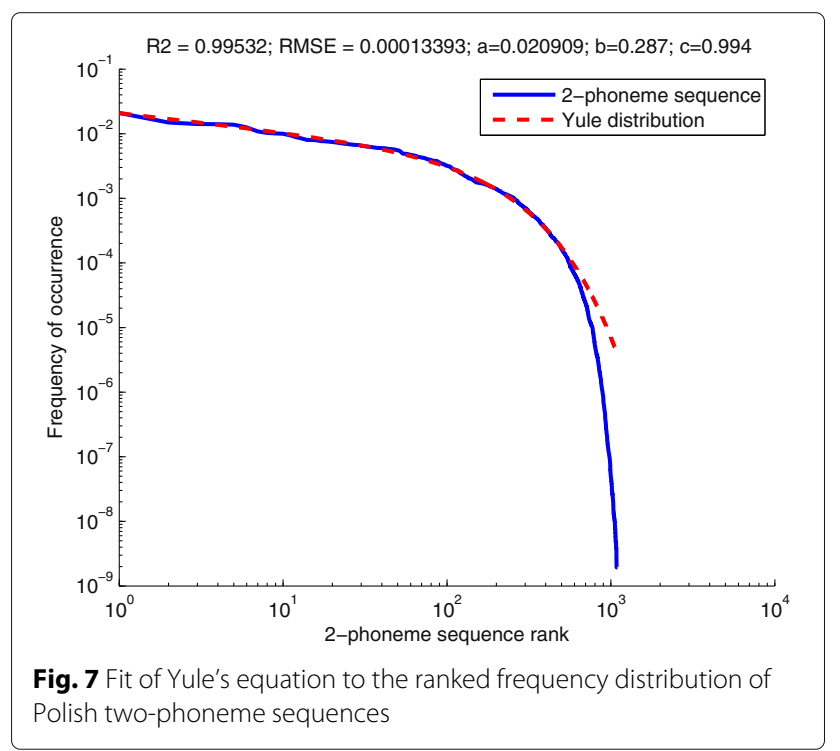




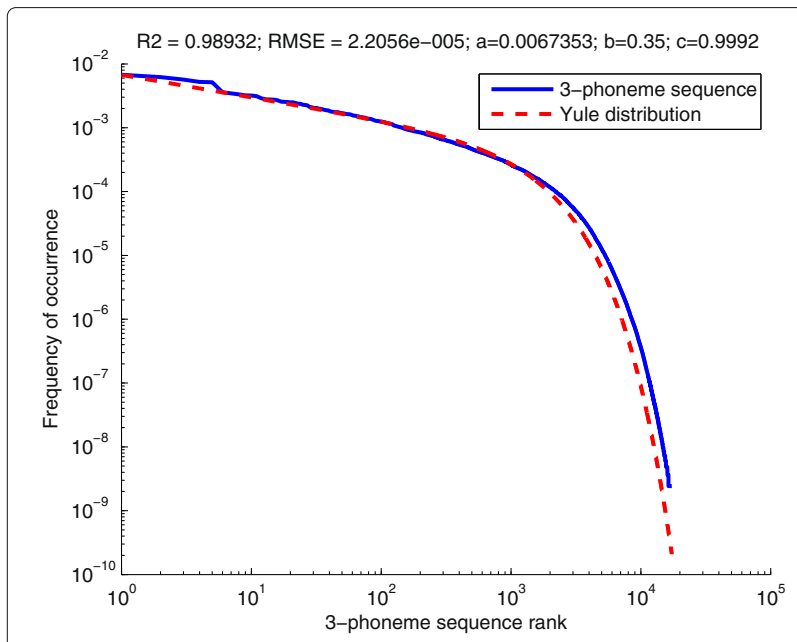

Fig. 8 Fit of Yule's equation to the ranked frequency distribution of Polish three-phoneme sequences

a sufficient large $n$ value. The perplexity $P P(W)$ of the word-based language model is then defined as [17]:

$$
P P(W)=2^{H(W)}
$$

The comparison of perplexity $P P_{N}(W)$ values for the developed word-based $N$-gram language models for $N=1, \ldots, 3$, is presented in Table 17. The comparison of perplexity $P P_{N}(Q)$ values for the developed phonemebased $N$-gram language models for $N=1, \ldots, 3$, is presented in Table 18.

The $P P$ values, presented in Tables 17 and 18, show that the developed phoneme-based 3-gram language model has the lowest $P P$ value equal to 7.77 . The lower perplexity value for language model indicates a greater ability to predict sequence of speech components. A language model is rated as better if the perplexity $P P$ value is less. A language models with low perplexity indicate more predictable language. However, since the perplexity is not related to the complexity of recognizing some acoustic patterns, reducing the language model, perplexity does not guarantee an improvement in automatic speech recognition performance.

Table 16 Evaluation results of the fit of Yule's equation to the ranked frequency distribution of Polish phonemes $(n=1)$ and $n$-phoneme sequences for $n=2, \ldots, 5$

\begin{tabular}{llll}
\hline$n$ & Yule's equation & $R^{2}$ & $R M S E$ \\
\hline 1 & $Y_{r}=\frac{0.095948}{r^{0.149}} \cdot 0.94^{r}$ & 0.92198 & $6.7012 \cdot 10^{-3}$ \\
2 & $Y_{r}=\frac{0.020909}{r^{0.287}} \cdot 0.994^{r}$ & 0.99532 & $1.3393 \cdot 10^{-4}$ \\
3 & $Y_{r}=\frac{0.0067353}{r^{0.35}} \cdot 0.9992^{r}$ & 0.98932 & $2.2056 \cdot 10^{-5}$ \\
4 & $Y_{r}=\frac{0.0031449}{r^{0.35}} \cdot 0.9997^{r}$ & 0.98510 & $5.5017 \cdot 10^{-6}$ \\
5 & $Y_{r}=\frac{0.0019385}{r^{0.33}} \cdot 0.9998^{r}$ & 0.98028 & $2.6493 \cdot 10^{-6}$ \\
\hline
\end{tabular}

Table 17 Comparison of perplexity $P P_{N}(W)$ values for the developed word-based $N$-gram language model for $N=1, \ldots, 3$

\begin{tabular}{llrl}
\hline$N$ & Perplexity & Value & Word-based language model \\
\hline 1 & $P P_{1}(W)$ & 9317.1 & 1-gram word-based language model \\
2 & $P P_{2}(W)$ & 933.0 & 2-gram word-based language model \\
3 & $P P_{3}(W)$ & 278.9 & 3-gram word-based language model \\
\hline
\end{tabular}

Potential application of other statistical analysis results

The statistical analysis results for 4 and 5-word sequence occurrence are not presented in this paper. But these results can be helpful to develop advanced (4 and 5-gram) word-based language models for Polish. As previously written, the language modelling may be based on modelling of words, as well as sub-words (e.g., phonemes). Therefore, the statistics of higher than three-phoneme sequence can be used for developing advanced (higher than 3-gram) phoneme-based language models for Polish. The advanced word-based and phoneme-based language modelling, enables to develop a hybrid language models for out-of-vocabulary (OOV) word detection in large vocabulary conversational speech recognition (LVCSR) systems for the language $[62,63]$. The language model in most state-of-the-art LVCSR systems is still the $N$ gram, which assigns probability to the next word based on only the $N-1$ preceding words [64]. But the use of an additional phoneme-based language models improves efficiency of LVCSR systems [65]. Another improvement in an LVCSR system development is the use of higher than 4-gram language models, with particular emphasis on $N$-gram phoneme-based language models.

\section{Conclusions}

This paper presents the original results of statistical analysis of Polish language, performed by means of the orthographic language text corpus, obtained from the NCP corpus and the phonemic language corpus, developed through automatic grapheme-to-phoneme conversion of the orthographic language corpus. The results of statistical analysis of Polish language, enable to develop statistical word-based and phoneme-based language models, in order to be used for automatic speech recognition.

The results of the research on statistical analysis of Polish language were compared and are consistent to other results available in the literature [40-46, 66, 67].

Table 18 Comparison of perplexity $P P_{N}(Q)$ values for the developed phoneme-based $N$-gram language model for $N=1, \ldots, 3$

\begin{tabular}{llll}
\hline $\mathrm{N}$ & Perplexity & Value & Phoneme-based language model \\
\hline 1 & $P P_{1}(Q)$ & 22.08 & 1-gram phoneme-based language model \\
2 & $P P_{2}(Q)$ & 10.85 & 2-gram phoneme-based language model \\
3 & $P P_{3}(Q)$ & 7.77 & 3-gram phoneme-based language model \\
\hline
\end{tabular}


Taking into account the results available in the literature, it can be concluded that performed statistical analysis of the language was extensive. No results of the statistical analysis of $n$-phoneme sequence occurrence in Polish for $n>3$ were found in the literature. On the basis of the comparison results, the following conclusion can be drawn: The phonemic language corpus in Polish which used to perform statistical analysis of the language, was very huge (containing 1,263,248,497 phonemes) and the statistical analysis results, obtained and based on it, allows to develop statistical models of Polish language.

Additionally, the validation and evaluation of the obtained statistical data were performed. The frequency of the word occurrence in a language is well described by Zipf's law. The validation of statistical data for words was performed by the fit of Zipf's equation to the ranked frequency distribution of Polish words. Similar regularity was observed for frequency distribution of the phoneme occurrence for Polish language. The examination of frequency occurrence in 95 languages, presented in the literature [51], shows that phoneme frequencies are best described by Yule's equation [54]. The validation of the statistical data for phonemes was performed by the fit of Yule's equations to the ranked frequency distribution of Polish phonemes and n-phoneme sequences. According to the results available in the literature [51], it can be concluded that statistical data obtained as the result of performed statistical analysis of Polish language, based on the orthographic and phonemic language corpora, are correct.

Regularity presented in this paper, it is not an isolated case and similar regularity can be observed in other languages, so also for other language corpora, reflecting the state of contemporary language [51]. It should also be noted, that it seems to be valuable to provide similar fits for existing Polish text corpora for allowing the reader to assess the quality of the created phonemic language corpus. Similarly, it seems to be very valuable to confront word error rate and the perplexity of the language models, created by means of the existing Polish corpora with respect to a common test set. However, it is difficult to perform due to lack of access to other existing Polish text corpora of appropriate size and quality, except NCP corpus. Similarly, the author does not find any available phonemic language corpus for Polish. Therefore, the author attempts to create his own phonemic language corpus with the use of G2P conversion of the existing available orthographic language corpus for Polish (NCP). Since this problem seems to be very important, the author is planning to bring this subject up in the future publications.

The developed word-based and phoneme-based language models were also presented in this paper, as an example of practical applications of the obtained statistical data of Polish language. The obtained statistical data open up further opportunities to continue research on improving automatic speech recognition in Polish. The plan for future research includes the development of statistical word-based and subword-based language models for Polish. The word-based and subword-based language modelling, enables to develop a hybrid language models for out of vocabulary word detection in large vocabulary conversational speech recognition [64, 68-70].

\section{Acknowledgements}

This work was supported by the Polish Ministry of Science and Higher Education funding for statutory activities.

\section{Competing interests}

The authors declare that they have no competing interests.

Received: 15 April 2016 Accepted: 8 February 2017

Published online: 28 February 2017

\section{References}

1. L Rabiner, B Juang, Fundamentals of Speech Recognition. Prentice Hall signal processing series. (PTR Prentice Hall, USA, 1993)

2. JR Bellegarda, C Monz, State of the art in statistical methods for language and speech processing. Comput. Speech Lang. 35, 163-184 (2016)

3. L Rabiner, B Juang, Encyclopedia of Language and Linguistics, Statistical methods for the recognition and understanding of speech. (Elsevier, Amsterdam, 2005)

4. S Sakti, K Markov, S Nakamura, W Minker, in Incorporating Knowledge Sources into Statistical Speech Recognition, vol 42 of Lecture Notes in Electrical Engineering. Statistical Speech Recognition (Springer US, USA, 2009), pp. 19-53

5. J Bellegarda, Large vocabulary speech recognition with multispan statistical language models. IEEE Transa. Speech Audio Process. 8 76-84 (2000)

6. P Kłosowski, in Computer Nerworks vol 79 of Communications in Computer and Information Science, ed. by A Kwiecien, P Gaj, and P Stera. Speech processing application based on phonetics and phonology of the polish language. 17th International Conference Computer Networks, Ustron, Poland, Jun 15-19 (Springer-Verlag, Berlin, 2010), pp. 236-244

7. P Kłosowski, Improving speech processing based on phonetics and phonology of Polish language. Przegląd Elektrotechniczny. 89, 303-307 (2013)

8. J Izydorczyk, P Kłosowski, Acoustic properties of Polish vowels. Bull. Pol. Acad. Sci. Tech. Sci. 47(1), 29-37 (1999)

9. J Izydorczyk, P Kłosowski, in International Conference Programable Devices and Systems PDS2001 IFAC Workshop, Gliwice November 22nd - 23rd. Base acoustic properties of Polish speech (IFAC, Gliwice, 2001), pp. 61-66

10. P Kłosowski, A Dustor, J Izydorczyk, J Kotas, Slimok J, in Computer Networks, CN 2014. vol 431 of Communications in Computer and Information Science, ed. by A Kwiecien, P Gaj, and P Stera. Speech recognition based on open source speech processing software. 21st International Science Conference on Computer Networks (CN), Brunow, Poland, Jun 23-27 (Springer-Verlag, Berlin, 2014), pp. 308-317

11. A Dustor, Kłosowski P, in Computer Networks, CN 2013. vol 370 of Communications in Computer and Information Science, ed. by A Kwiecien, P Gaj, and Stera P. Biometric voice identification based on Fuzzy Kernel Classifier. 20th International Conference on Computer Networks (CN), Lwowek Slaski, Poland, Jun 17-21 (Springer-Verlag, Berlin, 2013), pp. 456-465

12. A Dustor, P Kłosowski, J Izydorczyk, in 2014 International Conference on Multimedia Computing and Systems (ICMCS). Speaker recognition system with good generalization properties. International Conference on Multimedia Computing and Systems (ICMCS), Marrakech, Morocco, Apr 14-16 (IEEE, USA, 2014), pp. 206-210

13. A Dustor, P Kłosowski, J Izydorczyk, in Computer Networks, CN 2014. vol 431 of, Communications in Computer and Information Science, ed. by A Kwiecien, P Gaj, and P Stera. Influence of Feature Dimensionality and 
Model Complexity on Speaker Verification Performance. 21st International Science Conference on Computer Networks (CN), Brunow, Poland, Jun 23-27 (Springer-Verlag, Berlin, 2014), pp. 177-186

14. P Kłosowski, A Dustor, J Izydorczyk, in Computer Networks, CN 2015. vol 522 of Communications in Computer and Information Science, ed. by P Gaj, A Kwiecien, and P Stera. Speaker verification performance evaluation based on open source speech processing software and timit speech corpus. 22nd International Conference on Computer Networks (CN), Brunow, Poland, Jun 16-19 (Springer-Verlag, Berlin, 2015), pp. 400-409

15. A Dustor, P Kłosowski, J Izydorczyk, R Kopanski, in Computer Networks, CN 2015. vol 522 of Communications in Computer and Information Science, ed. by P Gaj, A Kwiecien, and P Stera. Influence of Corpus Size on Speaker Verification. 22nd International Conference on Computer Networks (CN), Brunow, Poland (Springer-Verlag, Berlin, 2015), pp. 242-249

16. P Kłosowski, Dustor A, in Computer Networks, CN 2013. vol 370 of Communications in Computer and Information Science, ed. by A Kwiecien, P Gaj, and P Stera. Automatic Speech Segmentation for Automatic Speech Translation. 20th International Conference on Computer Networks (CN), Lwowek Slaski, Poland, Jun 17-21 (Springer-Verlag, Berlin, 2013), pp. 466-475

17. F Jelinek, Statistical Methods for Speech Recognition. Language, Speech, \& Communication: A Bradford Book. (MIT Press, USA, 1997)

18. S Furui, Recent progress in corpus-based spontaneous speech recognition. IEICE Trans. Inf. Syst. E88D, 366-375 (2005)

19. M Adda-Decker, Corpus for automatic speech recognition. Revue Francaise De Linguistique Appliquee. 12, 71-84 (2007)

20. A Przepiórkowski, M Bańko, RL Górski, B Lewandowska-Tomaszczyk, The National Corpus of Polish (in Polish: Narodowy Korpus Języka Polskiego). (Wydawnictwo Naukowe PWN, Warszawa, 2012)

21. A Przepiórkowski, RL Górski, B Lewandowska-Tomaszczyk, Łaziński M, in Proceedings of the Sixth International Conference on Language Resources and Evaluation, LREC 2008. Towards the national corpus of Polish (Marrakech, ELRA, 2008)

22. RL Górski, B Lewandowska-Tomaszczyk, M Bańko, P Pęzik, M Łaziński, A Przepiórkowski, Practical applications of the National Corpus of Polish. Prace Filologiczne. 63, 231-240 (2012)

23. J Hirschberg, CD Manning, Advances in natural language processing. Science. 349, 261-266 (2015)

24. Association International Phonetic, Handbook of the International Phonetic Association: A Guide to the Use of the International Phonetic Alphabet. A Regents publication. (Cambridge University Press, UK, 1999)

25. R Sussex, P Cubberley, The Slavic Languages. Cambridge Language Surveys. (Cambridge University Press, UK, 2006)

26. J Wells, in Handbook of Standards and Resources for Spoken Language Systems. vol Part IV, section B, ed. by D Gibbon, R Moore, and R Winski. SAMPA computer readable phonetic alphabet (Mouton de Gruyter, Berlin and New York, 1997)

27. M Razavi, R Rasipuram, MM Doss, Acoustic data-driven grapheme-to-phoneme conversion in the probabilistic lexical modeling framework. Speech Commun. 80, 1-21 (2016)

28. RM Kaplan, M Kay, Regular models of phonological rule systems. Comput. Linguist. 20, 331-378 (1994)

29. M Steffen-Batóg, The problem of automatic phonemic transcription of written Polish. Biuletyn Fonograficzny. 14, 75-86 (1973)

30. M Steffen-Batóg, in Polish: Automatyzacja transkrypcji fonematycznej tekstów polskich. Automatic phonemic transcription of Polish texts (Wydawnictwo Naukowe PWN, Warszawa, 1975)

31. M Steffen-Batóg, Nowakowski P, in Studia Phonetica Posnaniensia. Vol. 3, ed. by M Steffen-Batóg, W Awedyk. An algorithm for phonetic transcription of orthographic texts in Polish (Wydawnictwo Naukowe UAM, Poznań, 1993)

32. W Jassem, A phonemic transcription and syllable division rule engine. (Onomastica-Copernicus Research Colloquium, Edinburgh, 1996)

33. P Kłosowski, in Proceedings of 20th IEEE International Conference Signal Processing Algorithms, Architectures, Arrangements, and App.lications, September 21-23. Algorithm and implementation of automatic phonemic transcription for polish (Poznan University of Technology, Poznań, 2016), pp. 298-303

34. M Wypych, in Speech and Language Technology. Vol. 3. Implementation of phonenic transcription alghorithm (in Polish: Implementacja algorytmu transkrypcji fonematycznej) (Polskie Towarzystwo Fonetyczne, Poznań, 1999)
35. G Demenko, M Wypych, E Baranowska, Implementation of grapheme-to-phoneme rules and extended SAMPA alphabet in Polish text-to-speech synthesis. Speech Lang. Technol. 7(17) (2003)

36. P Przybysz, W Kasprzak, in 20136 th International Conferance on Human Systems Interactions (HSI), ed. by WA Paja, BM Wilamowski. The generation of letter-to-sound rules for grapheme-to-phoneme conversion. Conference on Human System Interaction. Gdansk Univ Technol; Univ Informat Technol \& Management; IEEE Ind Elect Soc (Gdansk University of Techlology, Gdansk, 2013), pp. 292-297

37. D Skurzok, B Ziółko, Ziółko M, in 7th Language \& Technology Conference, Poznań. Ortfon2 - tool for orthographic to phonetic transcription (Adam Mickiewicz University in Poznan, Poznan, 2015)

38. D Koržinek, $Ł$ Brocki, Marasek K, Polish grapheme-to-phoneme tool and service, CLARIN-PL digital repository (2016). http://hdl.handle.net/11321/ 295, (Online: 2016.08.01)

39. Wiktionary, Polish Language Dictionary (2015). https://pl.wiktionary.org/. Accessed 17 Feb 2017

40. W Jassem, Podstawy fonetyki akustycznej (eng. Rudiments of acoustic phonetics). (PWN, Warszawa, 1973)

41. P Łobacz, W Jassem, Fonotaktyczna analiza mówionego tekstu polskiego (eng. Phonotactic analysis of spoken Polish texts). Biuletyn Polskiego Towarzystwa Ję. 32, 179-195 (1974)

42. C Basztura, Rozmawiac z komputerem (Eng. To speak with computers), (1992)

43. B Ziółko, J Gałka, S Manandhar, RC Wilson, M Ziółko, in Human Language Technology: Challenges of the Information Society. Vol 5603 of Lecture Notes in Artificial Intelligence, ed. by Z Vetulani, H Uszkoreit. Triphone Statistics for Polish Language. 3rd Language and Technology Conference 2007, Poznan, Poland, Oct 05-07, (2009), pp. 63-73

44. B Ziółko, J Gałka, M Ziółko, Polish phoneme statistics obtained on large set of written texts. Comput. Sci. (AGH). 10, 97-106 (2009)

45. B Ziółko, Gałka J, in Computer Science and Information Technology (IMCSIT), Proceedings of the 2010 International Multiconference on. Polish phones statistics (AGH Univesity of Science and Technology, Krakow, 2010), pp. 561-565

46. B Ziółko, P Zelasko, Skurzok D, in 2014 XXII Annual Pacific Voice Conference (PVC). Statistics of diphones and triphones presence on the word boundaries in the Polish language. App.lications to ASR. Annual Pacific Voice Conference, AGH; Pacific Voice Speech Fdn, 2014. 22nd Annual Pacific Voice Conference (PVC) (Krakow, AGH Univesity of Science and Technology, 2014)

47. D Lightfoot, The development of language: Acquisition, change, and evolution. (Wiley-Blackwell, Hoboken, 1999)

48. D Biber, S Conrad, R Repp.en, Corpus linguistics: Investigating language structure and use. (Cambridge University Press, Cambridge, 1998)

49. R Facchinetti, M Rissanen, Corpus-based studies of diachronic English, vol. 31. (Peter Lang, 2006)

50. GK Zipf, Human behavior and the principle of least effort. J. Clin. Psychol. 6(3), 306-306 (1950)

51. Y Tambovtsev, C Martindale, Phoneme frequencies follow a yule distribution. SKASE J. Theor. Linguist. 4(2) (2008)

52. ST Piantadosi, Zipf's word frequency law in natural language: A critical review and future directions. Psychonimic Bull. Rev. 21, 1112-1130 (2014)

53. A Corral, G Boleda, R Ferrer-i Cancho, Zipf's law for word frequencies: word forms versus lemmas in long texts. Plos ONE. 10(7), e0129031 (2015). doi:10.1371/journal.pone.0129031

54. GU Yule, A mathematical theory of evolution, based on the conclusions of Dr.J. C. Willis, F.R.S. Phil. Trans. R. Soc. London B Biol Sci. 213(402-410), 21-87 (1925)

55. S Dziadzio, A Nabożny, A Smywiński-Pohl, B Ziółko, in Computer Science and Information Systems (FedCSIS) 2015 Federated Conference on. Comparison of language models trained on written texts and speech transcripts in the context of automatic speech recognition (Lodz University of Technology, Lodz, 2015), pp. 193-197

56. S Takahashi, T Morimoto, in 2012 International Conference on Asian Language Processing (IALP 2012), ed. by D Xiong, E Castelli, M Dong, and PTN Yen. N-gram Language Model Based on Multi-Word Expressions in Web Documents for Speech Recognition and Closed-Captioning (Soochow University, China, 2012), pp. 225-228

57. A Hatami, A Akbari, B Nasersharif, in 201321 st Iranian Conference on Electrical Engineering (ICEE). N-gram Adaptation Using Dirichlet Class 
Language Model Based on Part-of-Speech for Speech Recognition (Ferdowsi University of Mashhad, Mashhadm, 2013)

58. M Bahrani, H Sameti, N Hafezi, S Momtazi, in New Frontiers in App.lied Artificial Intelligence, vol 5027 of Lecture Notes in Artificial Intelligence, ed. by NT Nguyen, L Borzemski, A Grzech, and M Ali. New word clustering method for building n-gram language models in continuous speech recognition systems (Springer, Berlin, 2008), pp. 286-293

59. B Rapp, in 2008 International Multiconference on Computer Science and Information Technology (IMCSIT), Vols 1 and 2, ed. by M Ganzha, M Paprzycki, and T PelechPilichowski. N-gram language models for Polish language. Basic concepts and applications in automatic speech recognition systems (IEEE Computer Society Press, Los Alamitos, 2008), pp. 295-298

60. D Klakow, P Jochen, Testing the correlation of word error rate and perplexity. Speech Commun. 38(1-2), 19-28 (2002)

61. T Cover, J Thomas, Wiley series in telecommunications: Elements of information theory. (John Wiley and Sons, USA, 1991)

62. PYu, FTB Seide, in Interspeech. A hybrid word/phoneme-based app.roach for improved vocabulary-independent search in spontaneous speech (Citeseer, Jeju Island, 2004)

63. V Chunwijitra, A Chotimongkol, C Wutiwiwatchai, A hybrid input-type recurrent neural network for Ivcsr language modeling. EURASIP J. Audio Speech Music Process. 2016(1), 15 (2016)

64. A Yazgan, M Saraclar, in Acoustics, Speech, and Signal Processing, 2004. Proceedings.(ICASSP'O4). IEEE International Conference on. Hybrid language models for out of vocabulary word detection in large vocabulary conversational speech recognition. vol 1 (IEEE, 2004), pp. I-745

65. M Larson, Sub-word-based language models for speech recognition: implications for spoken document retrieval. Whorkshop on Language Modeling and Information Retrieval (2001)

66. A Czardybon, O Hellwig, W Petersen, in Advances in Natural Language Processing. vol 8686 of Lecture Notes in Artificial Intelligence, ed. by A Przepiorkowski, M Ogrodniczuk. Statistical Analysis of the Interaction between Word Order and Definiteness in Polish. Polish Acad Sci, Inst Comp Sci, 2014. 9th International Conference on Natural Language Processing (NLP), Warsaw, Poland, Sep 17-19 (Polish Academy of Science, Institute of Conputer Scince, Warsaw, 2014), pp. 144-150

67. P Mandera, E Keuleers, Z Wodniecka, M Brysbaert, Subtlex-pl: subtitle-based word frequency estimates for Polish. Behav. Res. Methods. 47, 471-483 (2015)

68. JR Bellegarda, Large vocabulary speech recognition with multispan statistical language models. IEEE Trans. Speech Audio Process. 8 76-84 (2000)

69. H Schwenk, Continuous space language models. Comput. Speech Lang. 21(3), 492-518 (2007)

70. MAB Shaik, E-D AMousa, R Schlüter, H Ney, in INTERSPEECH. Hybrid language models using mixed types of sub-lexical units for open vocabulary German LVCSR (International Speech Communication Association (ISCA), Baixas, 2011), pp. 1441-1444

\section{Submit your manuscript to a SpringerOpen ${ }^{\circ}$ journal and benefit from:}

- Convenient online submission

- Rigorous peer review

- Immediate publication on acceptance

- Open access: articles freely available online

- High visibility within the field

- Retaining the copyright to your article

Submit your next manuscript at $\gg$ springeropen.com 